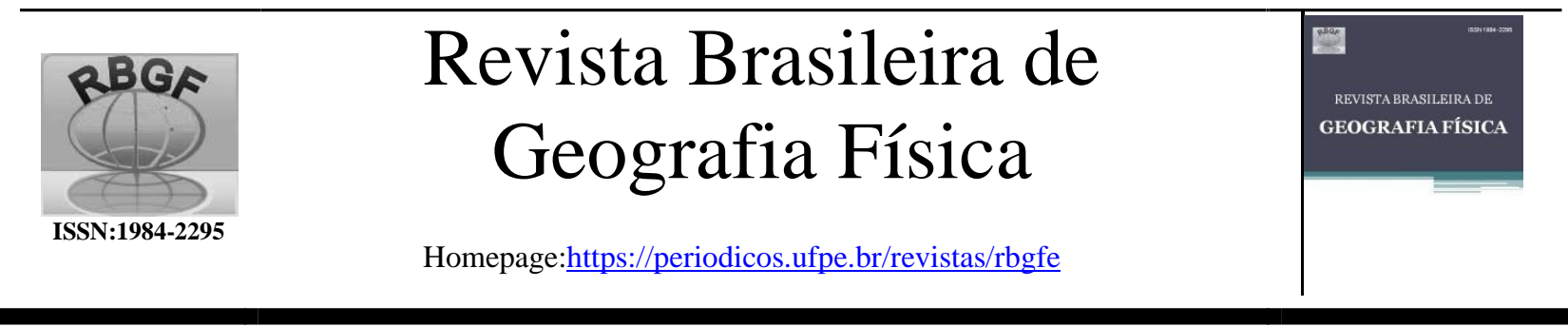

\title{
Diferentes Distúrbios Antrópicos na Paisagem podem influenciar Padrões Florísticos e Estruturais da Mata Atlântica?
}

\begin{abstract}
Elisa de Morais Paschoal ${ }^{1}$; Arthur Duarte Vieira²; Thiago José Ornelas Otoni ${ }^{3}$. Aglaia Maciel Gripp ${ }^{4}$; Jéssica Pereira Freire $^{5}$; Pablo Lopes Alves ${ }^{6}$; Anne Priscila Dias Gonzaga ${ }^{7}$; Evandro Luiz Mendonça Machado ${ }^{8}$

1, 2, 3 Mestre em Ciência Florestal pela Universidade Federal dos Vales do Jequitinhonha e Mucuri, 39100-000, Diamantina-Minas Gerais, Brasil, elisapaschoal@gmail.com, arthur.duartevieira@gmail.com, tj.otoni@gmail.com. ${ }^{4,5}$ Mestrando pelo Programa de Pós Graduação em Ciência Florestal, Universidade Federal dos Vales do Jequitinhonha e Mucuri, 39100-000, Diamantina-Minas Gerais, Brasil, aglaiagripp@gmail.com, jessiiicapf@outlook.com, pablo1lopes@hotmail.com.7,8 Professor na Universidade Federal dos Vales do Jequitinhonha e Mucuri 39100-000, Diamantina-Minas Gerais, Brasil, diaspri@gmail.com, machadoelm@gmail.com.
\end{abstract} Artigo recebido em 20/04/2020 e aceito em 10/06/2021

\section{R E S U M O}

Este estudo teve por objetivo descrever e comparar as diversidades alfa e beta e estrutura do componente arbóreo em remanescente de Floresta Estacional Semidecidual. A vegetação arbórea foi amostrada em duas bordas em contato com pastagem (BP), cafeicultura (BC), e no interior do fragmento (INT). Foram amostrados no total 2.840 indivíduos, identificados em 56 famílias, 144 gêneros e 271 espécies (94 na BC, 128 BP e 178 INT). Os trechos de borda foram caracterizados por maior densidade e menor área basal que o interior, indicando a influência de distúrbios. As variações na composição florística estrutural das comunidades arbóreas sofreram influência das variações ambientais regionais e locais, além do histórico de uso da área, conforme as Teorias de Nicho e do Distúrbio Intermediário.

Palavras-chave: Fitossociologia, Teoria do Distúrbio intermediário, Reserva da Biosfera da Serra do Espinhaço.

\section{Different Anthropic Disturbances in the Landscape can influence Floristic and Structural Patterns of the Atlantic Forest?}

This study aimed to describe and compare the floristic and structural component of the tree component, as well as the alpha and beta diversity, as well as the floristic similarity of a remnant of Semideciduous Forest. The tree vegetation was sampled at two edges in contact with pasture (BP) and coffee growing (BC), and inside the fragment (INT). 2.840 individuals were sampled, identified in 56 families, 144 genera and 271 species (94 BC, 128 BP and 178 INT). The border stretches were characterized by higher density and smaller basal area than the interior, indicating the occurrence of disturbances. The variations in the structural floristic composition of the tree communities wereinfluenced by regional and local environmental variations, as well as the historical use of the area, according to Niche and Intermediate Disturbance Theories.

Keywords:Phytosociology, Intermediate Disturbance Theory, Serra do Espinhaço Biosphere Reserve.

\section{Introdução}

Os ecossistemas florestais possuem mecanismos para reagir a alterações ambientais, absorver seus impactos e manter sua estrutura e funções ecológicas estáveis, de forma a permitir a manutenção do equilíbrio ecológico (Tivy, 1993; Turner et al, 1995). Todavia, estudos em florestas tropicais apontam que as modificações ambientais antropogênicas têm se tornado mais frequentes, de maior escala e mais intensas ao longo dos anos (Hobbs, 2002; Velazco et al, 2019). Em cenários de mudanças climáticas globais, tais modificações ambientais podem trazer consequências irremediáveis à dinâmica dos ecossistemas tropicais (Raymundo et al, 2019).

Deste modo, a fragmentação dos ecossistemas como consequência das atividades antrópicas representa, na atualidade, uma das

Paschoal., E., M.., A., D., Otoni., T., J., O., Gripp., A., M., Freire., J., P., Alves., P., L., Gonzaga., A., P., D., Machado., E., $L ., M$. 
principais ameaças a biodiversidade (Xie et al, 2017; Santos et al, 2020). Os fragmentos remanescentes, por possuírem áreas de habitat menores, acabam suportando populações também menores, e onde os riscos de extinção são mais comuns (Porto et al, 2018). Isto porque o isolamento das populações leva à depreciação do fluxo gênico, aumento da endogamia e perda da heterozigose, favorecendo a ocorrência da extinção local ou até mesmo regional (Porto et al, 2018; Cruz et al, 2018).

Tais consequências são ainda mais preocupantes quando ocorrem em ambientes que apresentam fragilidade ambiental, ou seja, quando os recursos naturais têm sido explorados durante séculos, incluindo, por exemplo, a ocupação antrópica na região da Mata Atlântica, o que proporcionou modificações na paisagem em larga escala e fragmentação florestal (Santos et al, 2020;Laurance, 2009; Ribeiro et al, 2009).Os altos níveis de fragmentação ainda observados atualmente, assim como, a contínua perda de habitat em toda a Mata Atlântica, têm gerado várias preocupações na comunidade científica (Joly et al, 2014; Esser et al, 2019).

Preocupação esta que se estende à região da Serra do Espinhaço, visto que, a fragmentação provocada pela extração de areia, garimpo, uso do fogo e atividades de pastagem, têm prejudicado o equilíbrio natural do meio, proporcionando, entre outros fatores, a perda do ecossistema e habitat da fauna e da flora (Giulietti et al, 2000; Pougy et al, 2019). A região do Alto Jequitinhonha abriga, formações vegetacionais da Mata Atlântica, com características naturais singulares, como as elevadas taxas de endemismo, as quais motivaram a criação de diversas modalidades de unidades de conservação de níveis nacional, estadual e municipal, sendo também reconhecida internacionalmente pela Organização das Nações Unidas para a Educação, a Ciência e a Cultura (UNESCO) como parte da Reserva da Biosfera da Serra do Espinhaço (MMA, 2010; Andrade et al, 2015).

Assim, o estudo teve por objetivo descrever se diferentes distúrbios antrópicos existentes em um remanescente de Mata Atlântica, localizado na Reserva da Biosfera da Serra do Espinhaço, atuariam como preditores na florística e na estrutura do componente arbóreo. Buscou-se avaliar e comparar três trechos distintos, sendo um deles localizados no interior do remanescente e, os demais, em contato com as paisagens modificadas por atividades de pastagem e cafeicultura. O estudo é baseado nas seguintes hipóteses: (i) Espera-se que a flora e os parâmetros estruturais variem em virtude dos diferentes usos da terra presente em cada trecho; (ii) Espera-se que o interior apresente valores de riqueza, diversidade florística e estrutura superiores as áreas de bordas, devido ao menor impacto das ações antrópicas ali existentes.

\section{Material e métodos}

Caracterização da área de estudo - o estudo foi realizado na Reserva Particular de Patrimônio Natural - RPPN Fartura, unidade de conservação sob responsabilidade da Companhia de Energia Elétrica de Minas Gerais (CEMIG), com coordenadas $762.349,00 \mathrm{~m} \mathrm{~W}$ e $802,340,00 \mathrm{~S}$. A reserva possui área total de 1.477,86 hectares e está na Reserva da Biosfera da Serra do Espinhaço, no estado de Minas Gerais, Brasil (MMA, 2010; IEF, 2009).

O clima da região é classificado como tropical, com período seco entre abril a setembro, e úmido de novembro a março, com temperatura média anual em torno de $21,5^{\circ} \mathrm{C}$, correspondendo como transição entre Cwa e Aw, como categoriza Köppen (Baars et al, 1997; Sá Junior, 2009). A pluviosidade da região varia de acordo com as estações, podendo chegar em torno de $200 \mathrm{~mm}$ à 900 mm (Ferreira e Silva, 2012).

Dois tipos de solo ocorrem na região, Argissolo vermelho-amarelo e Latossolo vermelho-amarelo, este último se manifesta principalmente ao sul do município (FEAN, 2010). Fitogeograficamente a região se localiza em transição entre os biomas do Cerrado e a Mata Atlântica, com a maior parte da RPPN coberta por este último bioma, especialmente por remanescentes de Floresta Estacional Semidecidual em formação secundária, sob diferentes estágios de sucessão ecológica.

$\mathrm{O}$ trecho de borda com a pastagem (BP) possui altitude em torno de $860 \mathrm{~m}$ e aproximadamente a $300 \mathrm{~m}$ de um curso d'água. O relevo contém declividade fraca a moderada (IBGE, 2009) e a variação da altitude entre as parcelas não passa de $13 \mathrm{~m}$.

Já o trecho de borda florestal em contato com a cafeicultura (BC), possui altitude de aproximadamente $950 \mathrm{~m}$. O relevo é marcado por declividade moderada a forte (IBGE, 20009) e 
assim, a amplitude de variação da altitude entre as parcelas é maior que a observada no trecho da pastagem, atingindo $40 \mathrm{~m}$.

Em vários pontos da reserva observou-se atividades de corte seletivo de madeira, a extração de cascalho e, principalmente, a criação de gado nas áreas de floresta, como também o uso do fogo, que segundo relatos de moradores antigos estas seriam frequentes na estação seca. Tais eventos ocasionaram a abertura de clareiras, favorecendo a entrada de luz interna na floresta nos trechos de borda.
Sistema de amostragem e coleta de dados - foram selecionados três trechos de um fragmento de Floresta Estacional Semidecidual, cada um com tipo de uso e ocupação do terreno com diferenças de origem antrópica. Assim, foram selecionados para o presente estudo duas áreas de borda e uma área de interior, a saber: a) borda em contato com pastagem; b) borda em contato com cafeicultura, c) interior. (Figura 1).

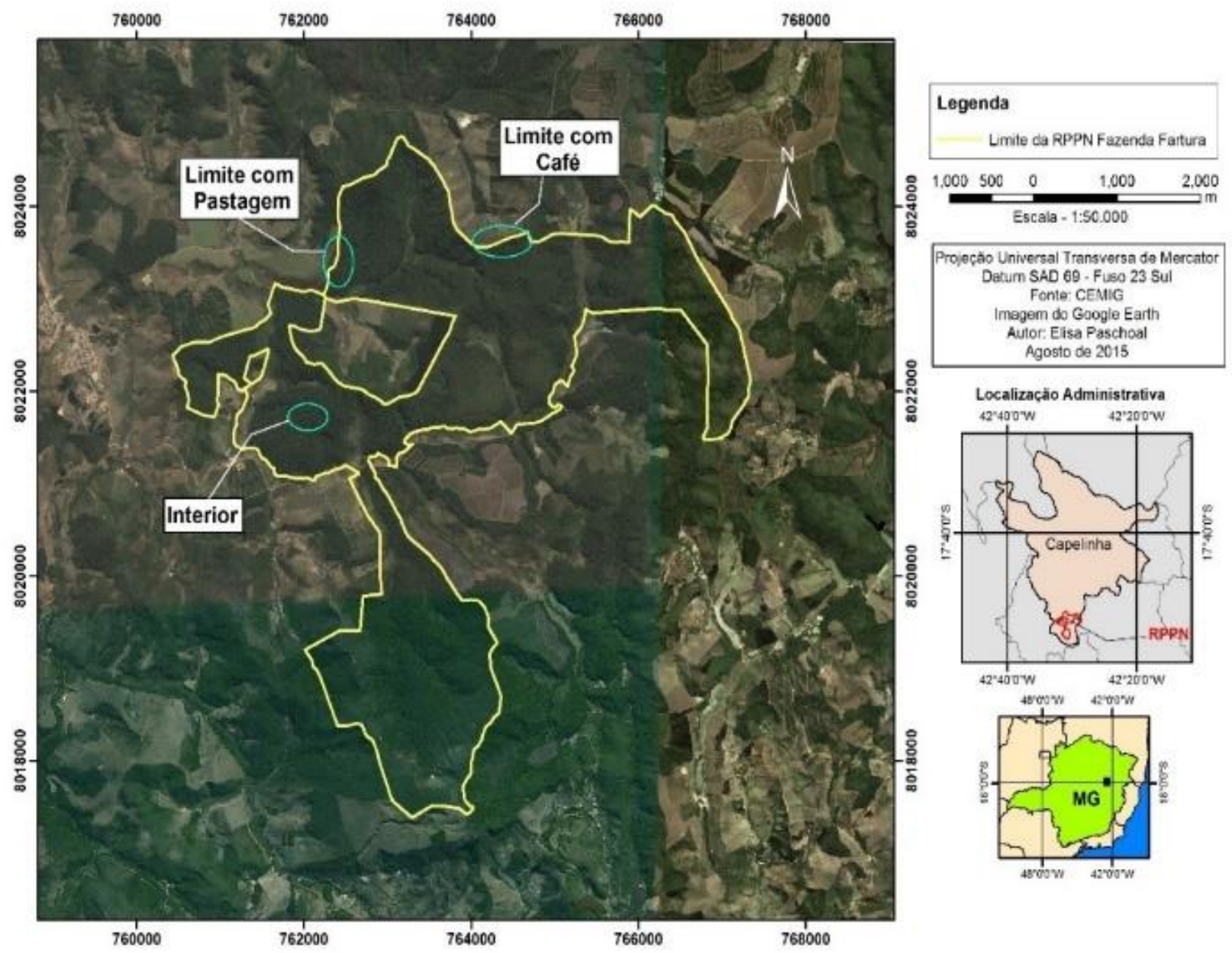

Figura 1. Trechos de um fragmento de Mata Atlântica selecionados para amostragem da vegetação arbóreaem um fragmento de Mata Atlântica na Unidade de Conservação RPPN Fartura, Reserva da Biosfera da Serra do Espinhaço.

Para a amostragem da vegetação arbórea nos trechos de borda, foram estabelecidos três transectos perpendiculares ao limite de cada uma delas que distavam $50 \mathrm{~m}$ entre si. Em cada um destes foram alocadas cinco parcelas de $10 \times 40$ $\mathrm{m}$, equidistantes $10 \mathrm{~m}$, totalizando 15 parcelas em cada borda. Nas parcelas foram mensurados todos indivíduos arbóreos vivos com diâmetro à altura do peito $(\mathrm{DAP}) \geq 5 \mathrm{~cm}$.

Para os dados do interior utilizou-se dados do levantamento da comunidade arbustiva-arbórea realizado por Vieira (2015), no qual foram 
alocadas 56 parcelas permanentes de $400 \mathrm{~m}^{2}$, e mensurados todos os indivíduos arbóreos vivos com diâmetro à altura do peito $(\mathrm{DAP}) \geq 5 \mathrm{~cm}$. No presente estudo, para compatibilizar o esforço amostral realizado nas bordas foram selecionados aleatoriamente 15 das 56 parcelas amostradas por Vieira (2015).

Para a identificação do material botânico coletado em todos os trechos utilizou-se a literatura científica, além da consulta a especialistas e o acervo do Herbário Dendrológico Jeanine Felfili (HDJF) da Universidade Federal dos Vales do Jequitinhonha e Mucuri (UFVJM), onde as amostras botânicas encontram-se depositadas. Para a classificação das espécies e famílias botânicas foi adotado o sistema APG IV - Angiosperm Phylogeny Group, sendo a grafia e sinonímias nomenclaturais verificadas de acordo com o banco de dados The PlantList, versão 1.1.

Análise dos Dados - a riqueza de espécies observada em cada trecho amostrado foi comparada por meio do teste de Kruskal-Wallis, seguido pelo teste de Dunn a 0,05 de significância, e pela confecção de curvas de rarefação (Lepš e Šmilauer, 1999) para cada trecho estudado (borda café, borda pastagem e interior). Foram utilizados os programas estatísticos Past 3.0 e Bioestat 5.0 para a realização das análises.

A similaridade florística existente nos três trechos estudados foi analisada por meio da confecção de diagramas de Venn, com auxílio do programa Venny 2.0 (Oliveiros, 2015).Também foram calculados os índices qualitativos $\mathrm{e}$ quantitativos, de Jaccard e Czekanowsk, respectivamente (Kent e Cokee, 1992).

A diversidade de espécies em cada borda e no interior do fragmento foi estimada de acordo com o Índice de Diversidade de Shannon $(\mathrm{H})$ e equabilidade de Pielou (J) (Brower e Zar, 1984). Os valores de Shannon encontrados para cada área foram testados estatisticamente, a 0,05 de significância, pelo teste $\mathrm{t}$ de Hutcheson (Zar, 1996).

Dentre as espécies identificadas, verificou-se a presença de espécies raras, considerando como rara aquelas representadas por apenas um indivíduo em toda a amostragem (Fontana e Sevegnani, 2012; Violle et al, 2017). Além disso, as espécies foram analisadas quanto ao registro de ocorrência para o estado de Minas Gerais, assim como, para o status do grau de ameaça das espécies. Para estas verificações foram utilizadas a Lista de Espécies da Flora do Brasil (2020), Lista Nacional Oficial de Espécies da Flora Ameaçadas de Extinção (MMA, 2014; MMA, 2014) e com base no banco de dados da Lista da Flora do Brasil 2020 (em construção).

A estrutura da vegetação foi caracterizada com base nos parâmetros fitossociológicos propostos por (Mueller-Dombois e Ellenberg, 2002) e a comparação entre os valores obtidos para cada trecho foi realizada pelo teste de Kruskal-Wallis, seguido pelo teste de Dunn ( $<<$ 0,05) (Zar, 1996).

Os indivíduos de cada trecho foram classificados de acordo com o tamanho do diâmetro por meio da comparação de classes. Para neutralizar a redução do número de indivíduos nas classes diamétricas maiores foram estabelecidas classes com amplitudes crescentes, conforme sugerido por Botrel et al. (2002).

\section{Resultados e discussão}

Foram amostrados 2.840 indivíduos, sendo 881 mensurados no interior do fragmento, 955 na borda em contato a pastagem e 1004 na borda em contato com o cafezal. Os números médios de indivíduos nas parcelas de cada trecho não foram diferentes pelo teste de Kruskal-Wallis $(\mathrm{p}=0,05)$.

No total, foram registradas 56 famílias botânicas, 144 gêneros e 271 espécies. Destas, 25 foram identificadas como morfoespécies (MF) e aguardam identificação por especialistas. As famílias com maior número de espécies foram Fabaceae (34 espécies), Myrtaceae (22), Annonaceae (15), Lauraceae (15) e Rubiaceae (12), que juntas representam cerca de $36 \%$ do total de espécies. Sendo assim, o fragmento de Mata Atlântica estudado demonstrou padrão florístico conhecido para outros fragmentos do bioma (Forzza et al, 2014; Lorenzoni-Paschoa et al, 2019).

No interior do fragmento houve predomínio das espécies de Fabaceae, Annonaceae e Rubiaceae, enquanto que em ambas as bordas as famílias com maior riqueza foram Fabaceae, Myrtaceae e Lauraceae.

Em relação ao número de indivíduos, Fabaceae, Euphorbiaceae e Salicaceae foram as mais importantes, com 543, 285 e 184 exemplares, respectivamente. No interior do fragmento houve predomínio de indivíduos das

2268

Paschoal., E., M.., A., D., Otoni., T., J., O., Gripp., A., M., Freire., J., P., Alves., P., L., Gonzaga., A., P., D., Machado., E., L., M. 
famílias Fabaceae, Salicaceae e Lauraceae (183, 89 e 72 indivíduos, respectivamente), na BP o maior número de indivíduos foram registrados para Euphorbiaceae (251), Fabaceae (177) e Myrtaceae (69), e na BC destacaram-se as famílias Fabaceae (184), Myrtaceae (184) e Peraceae (105).

Em contraste com os dados apresentados acima, algumas famílias foram representadas por apenas uma espécie e único indivíduo, como por exemplo, Burseraceae, Erythroxylaceae e Oleaceae. Das 271 espécies identificadas, 85 foram representadas por apenas um indivíduo em toda a amostragem, sendo então consideradas raras, ou seja, quase um terço de toda riqueza florística amostrada $(31,4 \%)$ são de espécies com raridade.
A observação de espécies raras no fragmento corroborou o padrão considerado para a Mata Atlântica, uma vez que entre 9 e 39\% das espécies registradas no bioma são representadas pela amostragem de um único indivíduo por hectare (Ricklefs e Fangliang, 2016; Magurran 2013).

A comparação da riqueza florística entre os trechos amostrados por meio das curvas de rarefação (Figura 2) e do teste de Kruskall-Wallis indicou diferença significativa entre eles $(\mathrm{p}=$ 0,0007). O resultado do teste de Dunn apontou que BP (128) não diferiu estatisticamente dos trechos $\mathrm{BC}$ e interior. Todavia, houve diferença significativa entre a riqueza encontrada nos trechos BC (94) e interior (179).

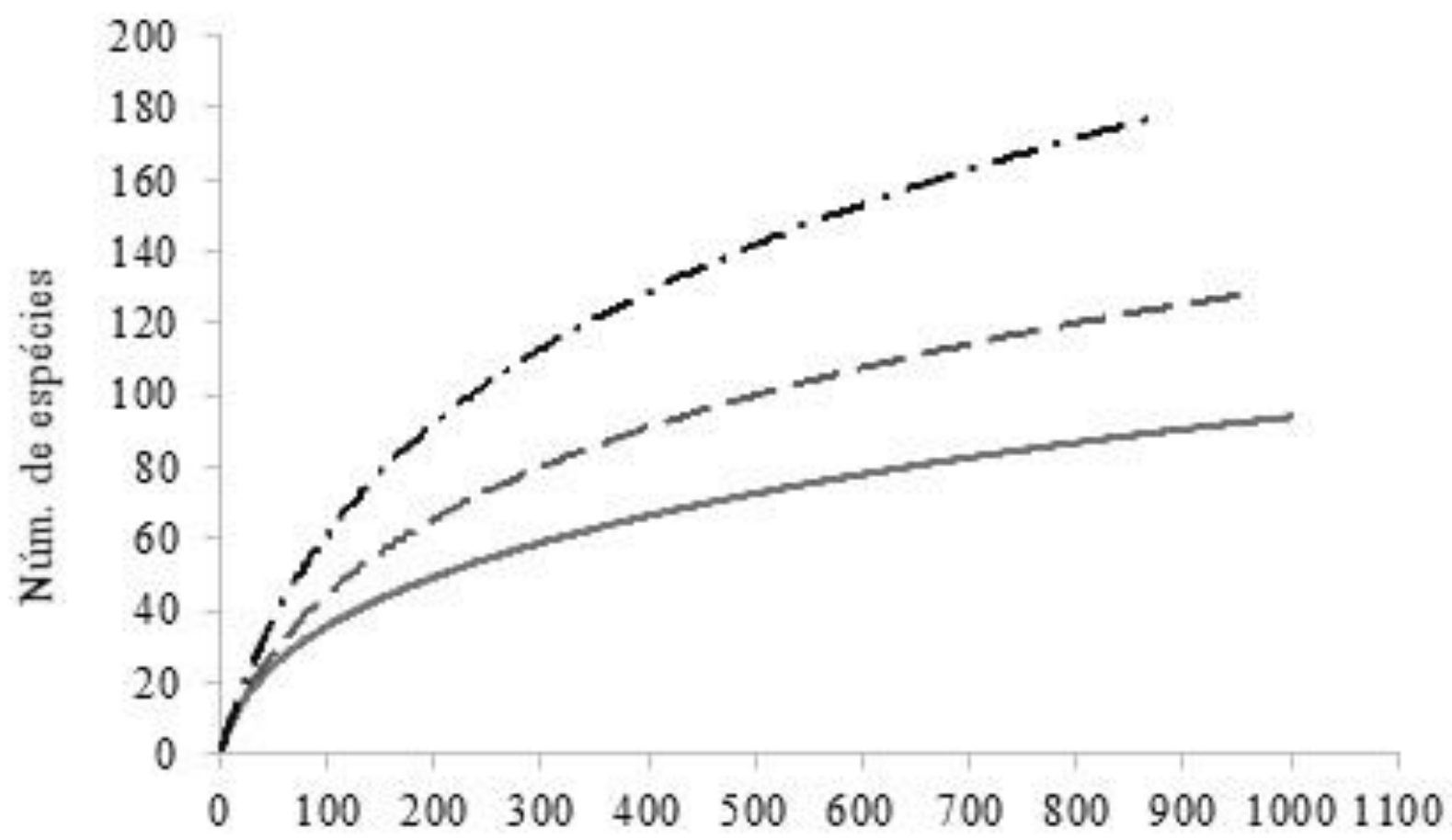

Núm. de individuos

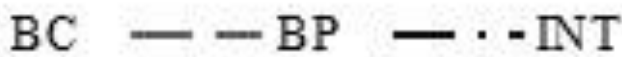

Figura 2. Curvas de rarefação da vegetação arbórea para os trechos amostrados em um fragmento de Mata Atlântica na Unidade de Conservação RPPN Fartura, Reserva da Biosfera da Serra do Espinhaço. Onde: BC = trecho de borda em contato com café; BP: trecho de borda em contato com pastagem; INT = trecho localizado no interior do fragmento.

As diferenças na riqueza e diversidade de espécies, com maiores valores registrados no

Paschoal., E., M.., A., D., Otoni., T., J., O., Gripp., A., M., Freire., J., P., Alves., P., L., Gonzaga., A., P., D., Machado., E., L., M. 
interior do fragmento, sugerem que as bordas sofreram distúrbios mais intensos que o trecho do interior, sendo que o uso pretérito do fogo e a criação de gado no interior da floresta parecem ter sido os principais fatores de degradação em ambas as bordas (Silva e Schmitt, 2015; Chazdoen, 2016).

Contudo, é provável que a $\mathrm{BC}$ tenha alterado intensamente com os distúrbios de origem antrópica, pelo fato de ser mais acessível e mais antiga que a BP. Nessa perspectiva, os distúrbios acentuados nesta borda teriam alterado e até reduzido os padrões de riqueza e diversidade deste trecho em relação aos demais.

Apenas 32 espécies foram comuns aos três trechos (Figura 3). Os valores encontrados para os índices de similaridade Jaccard e Czekanowski foram inferiores a $50 \%$ o que indica que os trechos são dissimilares (Gauch, 1982), tanto em termos de composição florística, quanto ao tamanho das populações.

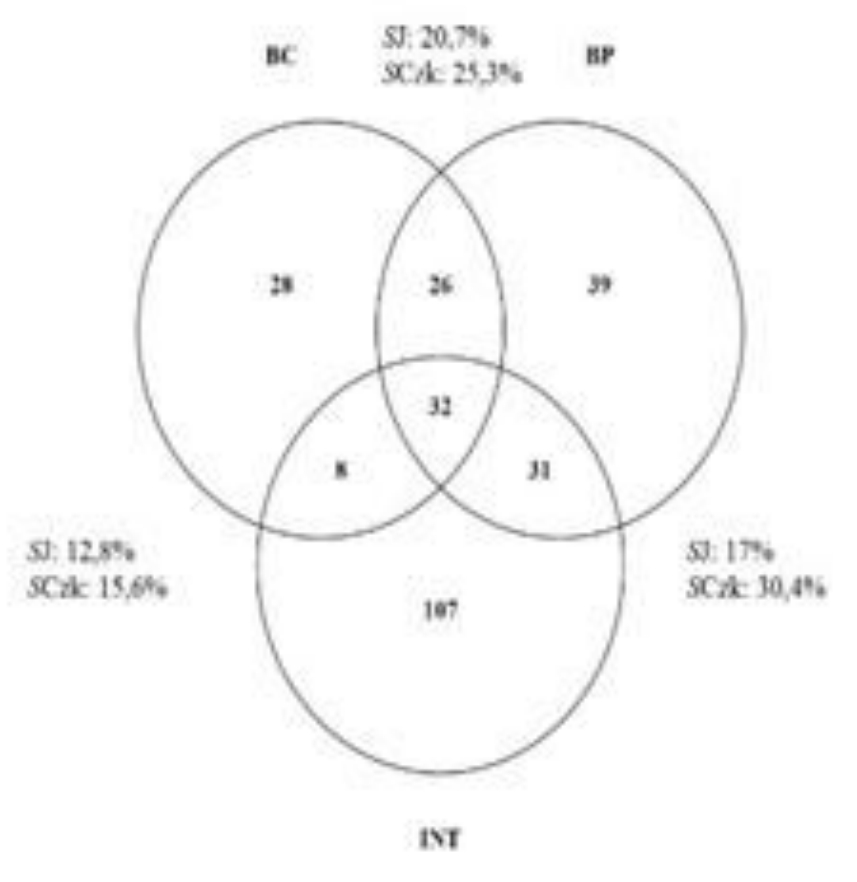

Figura 3. Compartilhamento das espécies arbóreas (DAP $\geq 5 \mathrm{~cm}$ ) entre os três trechos amostrados no fragmento de Mata Atlântica na Unidade de Conservação RPPN Fartura, Reserva da Biosfera da Serra do Espinhaço. Onde: BC = trecho de borda em contato com café; BP: trecho de borda em contato com pastagem; INT = trecho localizado no interior do fragmento; SJ = índice de similaridade de Jaccard; SCzk = índice de similaridade de Czekanowski.

Os três trechos amostrados apresentaram alta diversidade florística $\left(\mathrm{H}^{\prime}=4,58\right)$. Os valores obtidos pelo índice de Shannon e pelo teste $t$ de Hutcheson para cada trecho estudado foram BCBP com H' $=3,53-3,75$ e p <0,0001, BC-INT com $H^{\prime}=3,53-4,60$ e p $<0,0001$, BP-INT com $\mathrm{H}^{\prime}=3,75-7,60$ e $\mathrm{p}<0,0001$. O que revelou que a diversidade foi alta e significativamente diferente entre eles.

A riqueza e diversidade dos trechos estudados estão relacionadas às características físicas do Alto Jequitinhonha e ao histórico de uso da RPPN Fartura, isto considerando que diversos fatores abióticos são condicionantes para a geração e manutenção da diversidade biológica, e por esta razão, favoreceu o aumento da riqueza e da diversidade nessas áreas (Gonzaga et al, 2013; Costa et al, 2018).

Assim sendo, acredita-se que a Teoria de Nichos explicaria a alta diversidade encontrada, visto que, segundo esta teoria, diferentes espécies toleram condições bióticas e abióticas distintas, buscando recursos e formas eficientes de estabelecimento e então, ocupam ambientes diversos que se sobrepõem dentro de um mesmo habitat (Morandi, 2018). Como os trechos apresentam condições físicas e antrópicas muito variável (alta heretogeneidade ambiental) uma maior variedade de espécies écapaz de co-habitar 
ao longo das áreas amostradas, aumentando assim a riqueza e diversidade.

Nesse sentido, a Teoria de Nichos poderia também explicar a baixa similaridade florística encontrada entre os trechos, uma vez que a composição das espécies pode estar associada às variações ambientais e topográficas, típicas de cada trecho (Cruz et al, 2018;Gonzaga et al, 2017; Gonzaga et al, 2017).

Assim, a geração e manutenção da diversidade pode ser favorecida pela coexistência dos diferentes nichos ecológicos providos pelo ambiente. Além disso, a ocorrência de distúrbios, a complexidade do habitat, a adaptação aos microhabitats e a pressão por herbívora foram considerados como fatores principais que favorecem a coexistência de várias espécies em uma mesma floresta e promotores da elevada diversidade de árvores em florestas tropicais (Leigh et al, 2004)

Seguindo essa lógica, é provável que a variação da declividade entre os trechos estudados seja fator condicionador da heterogeneidade ambiental e que justificaria a diversidade no fragmento, visto que ao longo de um declive, a variação da temperatura e da umidade do solo criaria diferentes oportunidades de nicho para as espécies (Braga et al, 2015)

Associada a Teoria de Nichos, a alta diversidade encontrada para o conjunto dos trechos pode também estar relacionada à Teoria do Distúrbio Intermediário (Connel, 1978). Esta teoria pressupõe que ecossistemas florestais sujeitos a regimes intermediários de distúrbios tendem a apresentar elevada diversidade, e que na ausência ou sob regimes de distúrbio muito intensos a diversidade tende a diminuir (Rozendaal et al, 2019).

Os valores obtidos pela equabilidade de Pielou (J') indicaram que a alta diversidade está bem distribuída entre as unidades amostrais e entre os respectivos trechos, sendo $\mathrm{BC}\left(\mathrm{J}^{\prime}=0,78\right)$, BP $\left(\mathrm{J}^{\prime}=0,77\right)$, INT $\left(\mathrm{J}^{\prime}=0,89\right)$, sendo o total $\mathrm{J}^{\prime}=$ 0,82 .

As espécies consideradas mais importantes pelo índice de Valor de Importância (VI) não foram as mesmas para os três trechos. Na BC se destacaram as espécies Myrcia amazonica, Pera glabrata, Machaerium brasiliense, Guatteria sp, Amaioua guianensis, Kielmeyera
Assim, considerando o tempo de modificação do fragmento e a recente formação das bordas (BC e BP), é possível afirmar que a diferença de riqueza e diversidade do componente arbóreo entre os trechos tenham ocorrido, principalmente, devido ao histórico de uso e interferência humana na área, não se descartando, pois, o efeito de borda. Isto porque, seria necessário um espaço de tempo plausível para que modificações na estrutura e composição dos indivíduos ocorram em relação aos efeitos das alterações na paisagem, sendo condicionado, sobretudo, pelos ciclos de vida de espécies arbóreas que ocupam o interior, os quais tendem a ser longos e dependem de animais para sua dispersão (Metzger, 1998).

De maneira geral, este estudo demonstrou que os trechos detêm alta diversidade e riqueza de espécies, bem como espécies ameaçadas de extinção, o que realça ainda mais o valor da existência da RPPN Fartura, sendo necessário um manejo adequado e à adoção de medidas conservacionistas na região.

Ao analisar os parâmetros fitossociológicos (Tabela 1) observou-se que o efeito de borda ao longo do tempo provocou modificações também na estrutura, na composição de espécies e, consequentemente, as alterações dos processos ecológicos (Lôbo et al, 2011). Embora a heterogeneidade ambiental provocada pelas alterações de fatores abióticos possa favorecer o aumento da diversidade, a diminuição das áreas de habitat provocadas pela fragmentação, pode levar à redução e extinção local de espécies adaptadas àquele ambiente (Barbalho et al, 2015), que contribuíram para a relevância das espécies. Já que em termos de VI, na $\mathrm{BC}$, observou-se elevados valores de dominância relativa e densidade relativa foram característicos paras as espécies Myrcia amazonica, Pera glabrata, Machaerium brasiliense, Guatteriasp. 1 e Kielmeyera latrophyton. Por outro lado, Bowdichia virgilioides apresentou elevados valores de dominância relativa e mais baixa densidade. lathrophyton, Jacaranda jasminoides, Eremanthus erythropappus, Myrcia guianensis e Bowdichia virgilioides. $\mathrm{Na} \mathrm{BP}$ as espécies de maior VI foram Mabea fistulifera, Ocotea corymbosa, Inga marginata, Trichilia hirta, Casearia arborea, M. brasiliense, Cassia ferruginea, Cupania vernalis, Platypodium

Paschoal., E., M.., A., D., Otoni., T., J., O., Gripp., A., M., Freire., J., P., Alves., P., L., Gonzaga., A., P., D., Machado., E., L., $M$. 
elegans e Guatteria sp. 2. No trecho do interior, tiveram maior importância em termos de VI $C$. arborea, Machaerium nyctitans, Siparuna guianensis, Tachigali rugosa, A. guianensis, Guatteria nigrescens, Copaifera langsdorffii, O. corymbosa, J. jasminoides e Dalbergia nigra.

A análise dos parâmetros fitossociológicos que contribuíram para a relevância das espécies, em termos de VI, no interior, indicou que Casearia arborea e Machaerium nyctitans estiveram altos valores de dominância relativa e densidade relativa, ao passo que Amaioua guianensis e Copaifera langsdorfii apresentaram elevados valores de dominância relativa e mais baixa densidade relativa.

$\mathrm{Na} \mathrm{BP}$, Mabea fistulifera foi importante e apresentou o maior VI $(13,48 \%)$. A espécie

Tabela 1: Parâmetros fitossociológicos das espécies arbóreas (DAP $\geq 5 \mathrm{~cm}$ ) registradas em três trechos amostrados no fragmento de Mata Atlântica na Unidade de Conservação RPPN Fartura, Reserva da Biosfera da Serra do Espinhaço.

\begin{tabular}{|c|c|c|c|c|c|c|c|c|c|c|c|c|}
\hline \multirow{2}{*}{ Espécies } & \multicolumn{4}{|c|}{ Borda do Café } & \multicolumn{4}{|c|}{ Borda da Pastagem } & \multicolumn{3}{|c|}{ Interior } & \multirow[b]{2}{*}{ VI } \\
\hline & DR & FR & DoR & VI & DR & FR & DoR & VI & DR & FR & DoR & \\
\hline Abarema villosa & 0,29 & 0,90 & 0,13 & 0,44 & & & & & & & & \\
\hline Actinostemon concolor & & & & & 0,41 & 0,95 & 0,55 & 0,64 & 0,22 & 0,41 & 0,23 & 0,29 \\
\hline Actinostemon klotzschii & & & & & & & & & 0,22 & 0,41 & 0,50 & 0,38 \\
\hline Aegiphila fluminensis & & & & & & & & & 0,11 & 0,20 & 0,14 & 0,15 \\
\hline Aegiphila integrifolia & & & & & & & & & 0,11 & 0,20 & 0,32 & 0,21 \\
\hline Aegiphila lhotzkiana & 0,10 & 0,30 & 0,11 & 0,17 & 0,10 & 0,24 & 0,11 & 0,15 & & & & \\
\hline Alchornea triplinervia & & & & & & & & & 0,11 & 0,20 & 0,11 & 0,14 \\
\hline Allophylus edulis & & & & & & & & & 0,56 & 0,82 & 0,13 & 0,50 \\
\hline Allophylus racemosus & & & & & 0,20 & 0,24 & 0,07 & 0,17 & & & & \\
\hline Amaioua guianensis & 5,27 & 2,71 & 4,42 & 4,14 & 0,41 & 0,95 & 0,13 & 0,50 & 1,81 & 1,64 & 4,04 & 2,50 \\
\hline Amaioua intermedia & & & & & & & & & 0,34 & 0,20 & 0,09 & 0,21 \\
\hline Anadenanthera colubrina & & & & & 0,10 & 0,24 & 0,05 & 0,13 & 0,11 & 0,20 & 0,13 & 0,15 \\
\hline Andira ormosioides & & & & & & & & & 0,11 & 0,20 & 0,11 & 0,14 \\
\hline Andira sp. & & & & & 0,10 & 0,24 & 0,38 & 0,24 & & & & \\
\hline Aniba firmula & & & & & & & & & 0,56 & 0,41 & 0,14 & 0,37 \\
\hline Annona тисоsa & & & & & & & & & 0,11 & 0,20 & 0,02 & 0,11 \\
\hline Annona neolaurifolia & & & & & 0,10 & 0,24 & 0,03 & 0,12 & 1,36 & 1,43 & 1,17 & 1,32 \\
\hline Annona neosericea & & & & & & & & & 0,56 & 0,82 & 0,42 & 0,60 \\
\hline Annona sylvatica & 0,59 & 0,60 & 0,70 & 0,63 & 0,62 & 1,19 & 0,44 & 0,75 & 0,68 & 0,41 & 0,93 & 0,67 \\
\hline Aparisthmium cordatum & & & & & & & & & 0,22 & 0,41 & 0,09 & 0,24 \\
\hline Aralia warmingiana & & & & & & & & & 0,11 & 0,20 & 0,34 & 0,22 \\
\hline Aspidosperma cuspa & & & & & & & & & 0,11 & 0,20 & 0,05 & 0,12 \\
\hline Aspidosperma illustre & & & & & & & & & 0,56 & 0,61 & 0,41 & 0,53 \\
\hline Aspidosperma olivaceum & & & & & 0,10 & 0,24 & 0,09 & 0,14 & 0,11 & 0,20 & 0,29 & 0,20 \\
\hline
\end{tabular}

$0,10 \quad 0,30 \quad 0,12 \quad 0,17$

Aspidosperma pyrifolium

$$
0,10 \quad 0,24 \quad 0,03 \quad 0,12
$$

Paschoal., E., M.., A., D., Otoni., T., J., O., Gripp., A., M., Freire., J., P., Alves., P., L., Gonzaga., A., P., D., Machado., E., L., $M$. 
Revista Brasileira de Geografia Física v.014, n.04 (2021) 2265-2284

Aspidosperma spruceanum

$0,11 \quad 0,20 \quad 0,40 \quad 0,24$

Continuação

Astronium fraxinifolium

Bathysa australis

$\begin{array}{llllllll}1,78 & 1,19 & 1,74 & 1,57 & 1,02 & 1,23 & 2,28 & 1,51\end{array}$

Bauhinia forficata

Bowdichia virgilioides

$\begin{array}{lllllll}2,41 & 4,08 & 2,72 & 0,52 & 0,95 & 1,04 & 0,84\end{array}$

$\begin{array}{llll}1,13 & 0,41 & 0,99 & 0,84\end{array}$

$\begin{array}{llll}0,79 & 0,61 & 0,97 & 0,79\end{array}$

Brosimum guianense

$0,56 \quad 0,61 \quad 0,77 \quad 0,65$

Brosimum lactescens

Buchenavia tomentosa

$0,29 \quad 0,90 \quad 2,13$

Byrsonima ligustrifolia

Byrsonima stipulaceae

$\begin{array}{llllllll}0,29 & 0,30 & 1,43 & 0,67 & 0,10 & 0,24 & 0,04 & 0,13\end{array}$

Cabralea cangerana

$0,19 \quad 0,60 \quad 0,12 \quad 0,30$

Caesalpinia $\mathrm{sp}$

$\begin{array}{llllllll}1,79 & 2,10 & 1,74 & 1,88 & 0,10 & 0,24 & 0,03 & 0,12\end{array}$

Callisthene major

$0,59 \quad 1,50 \quad 1,05 \quad 1,05$

$0,10 \quad 0,24 \quad 0,03 \quad 0,12$

Calycorectes sp.

$\begin{array}{rrrrr}0,10 & 0,24 & 0,15 & 0,16\end{array}$

Calyptranthes clusiifolia

Campomanesia

guazumifolia

Campomanesia simulans

Campomanesia velutina

Casearia arborea

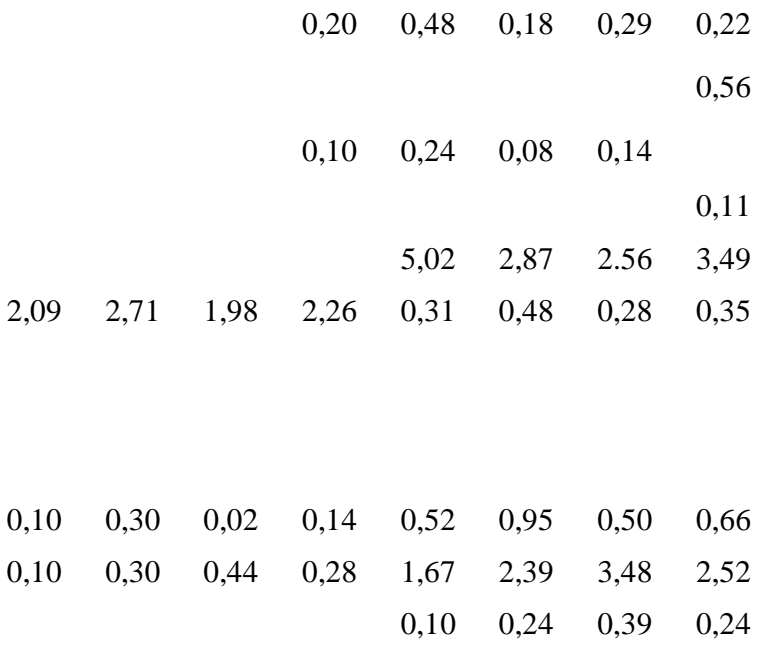

$0,11 \quad 0,20 \quad 0,03 \quad 0,11$

Casearia grandiflora

Casearia lasiophylla

Casearia obliqua

Casearia rupestris

Casearia sylvestris

Cassia ferruginea

Cecropia hololeuca

Cecropia pachystachya

Cedrela fissilis

Chionanthus ferrugineus

Chomelia sericea

Chrysochlamys

saldanhae

Cinnamomum

tomentulosum

Clavija nutans

Clethra scabra

Colubrina glandulosa

Copaifera langsdorffii

Cordia sellowiana

Cordiera sessilis

Coutarea hexandra

Croton floribundus

Croton salutaris

\begin{tabular}{|c|c|c|c|c|c|c|c|c|c|c|c|}
\hline & & & & & & & & 0,22 & 0,20 & 0,10 & 0,17 \\
\hline & & & & & & & & 0,56 & 0,61 & 1,47 & 0,88 \\
\hline & & & & & & & & 0,11 & 0,20 & 0,04 & 0,12 \\
\hline & & & & & & & & 1,47 & 0,82 & 3,13 & 1,81 \\
\hline 0,10 & 0,30 & 0,02 & 0,14 & 0,52 & 1,19 & 0,20 & 0,64 & & & & \\
\hline 0,29 & 0,30 & 0,12 & 0,22 & & & & & & & & \\
\hline & & & & & & & & 0,34 & 0,41 & 0,45 & 0,40 \\
\hline & & & & & & & & 0,11 & 0,20 & 0,03 & 0,11 \\
\hline & & & & & & & & 0,68 & 0,62 & 0,37 & 0,56 \\
\hline 0,10 & 0,30 & 0,22 & 0,20 & 0,20 & 0,48 & 0,40 & 0,36 & 1,70 & 1,63 & 2,93 & 2,09 \\
\hline & & & & 0,10 & 0,24 & 0,25 & 0,19 & 0,34 & 0,41 & 0,20 & 0,32 \\
\hline & & & & & & & & 0,11 & 0,20 & 0,04 & 0,12 \\
\hline & & & & 0,31 & 0,71 & 0,17 & 0,40 & 0,11 & 0,20 & 0,07 & 0,13 \\
\hline & & & & 0,10 & 0,24 & 0,05 & 0,13 & & & & \\
\hline & & & & & & & & 0,90 & 1,02 & 0,63 & 0,85 \\
\hline
\end{tabular}

Paschoal., E., M.., A., D., Otoni., T., J., O., Gripp., A., M., Freire., J., P., Alves., P., L., Gonzaga., A., P., D., Machado., E., L., M. 
Revista Brasileira de Geografia Física v.014, n.04 (2021) 2265-2284

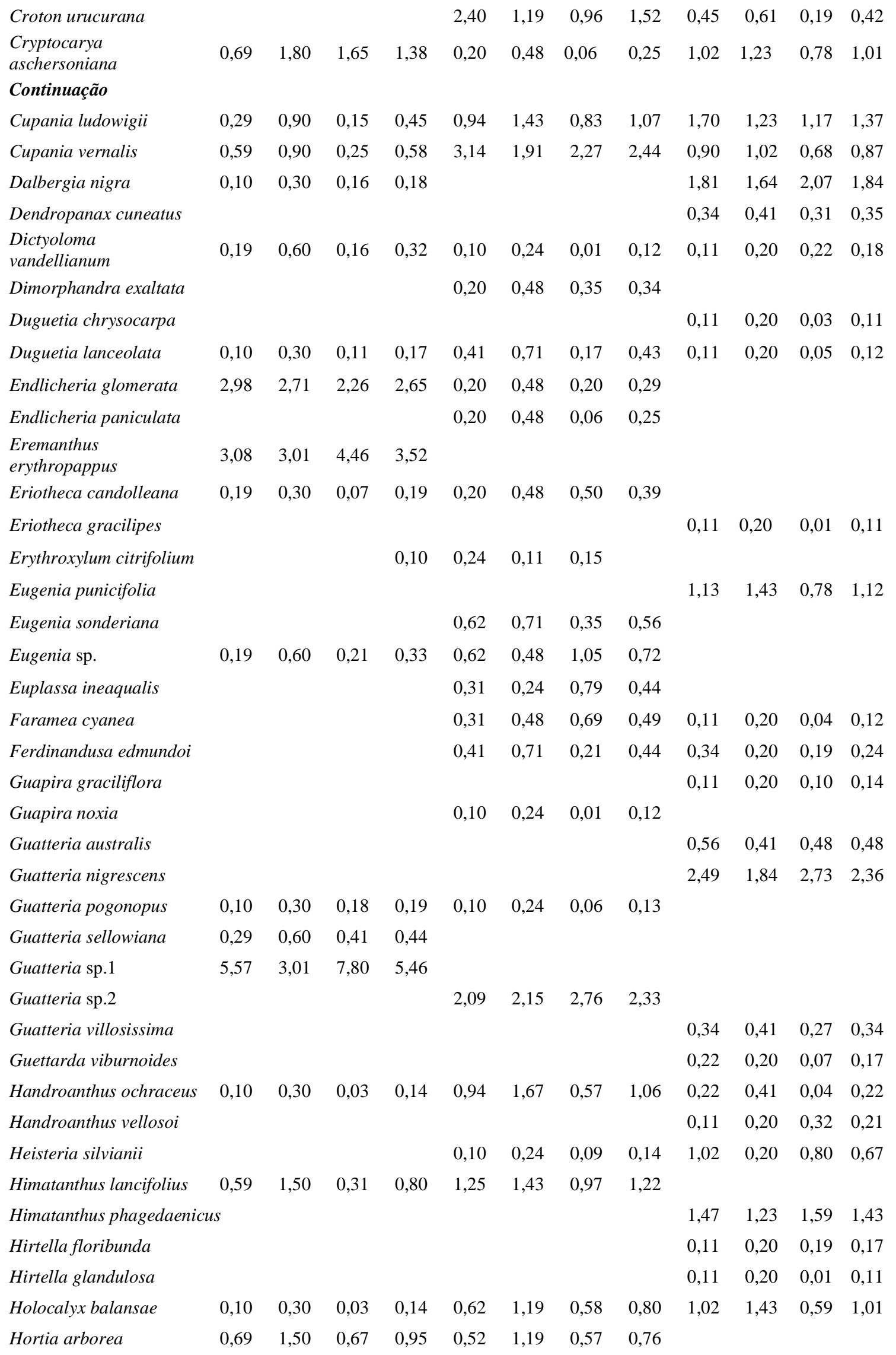

Paschoal., E., M.., A., D., Otoni., T., J., O., Gripp., A., M., Freire., J., P., Alves., P., L., Gonzaga., A., P., D., Machado., E., L., M. 
Revista Brasileira de Geografia Física v.014, n.04 (2021) 2265-2284

\begin{tabular}{|c|c|c|c|c|c|c|c|c|c|c|c|c|}
\hline Hortia brasiliana & & & & & & & & & 0,34 & 0,41 & 0,60 & 0,45 \\
\hline $\begin{array}{l}\text { Hymenolobium } \\
\text { janeirense }\end{array}$ & 0,10 & 0,30 & 0,15 & 0,18 & 0,20 & 0,48 & 0,39 & 0,36 & & & & \\
\hline \multicolumn{13}{|l|}{ Continuação } \\
\hline $\begin{array}{l}\text { Hyptidendron } \\
\text { asperrimum }\end{array}$ & 0,69 & 1,50 & 0,31 & 0,84 & 0,73 & 1,43 & 0,37 & 0,84 & 0,11 & 0,20 & 0,02 & 0,11 \\
\hline Ilex cerasifolia & & & & & & & & & 0,22 & 0,20 & 0,05 & 0,16 \\
\hline Inga cylindrica & & & & & & & & & 0,79 & 0,61 & 1,31 & 0,90 \\
\hline Inga ingoides & & & & & & & & & 0,11 & 0,20 & 0,30 & 0,20 \\
\hline Inga marginata & 1,99 & 2,41 & 1,65 & 2,01 & 4,81 & 2,63 & 5,36 & 4,27 & 0,34 & 0,41 & 0,19 & 0,31 \\
\hline Inga striata & & & & & & & & & 0,22 & 0,41 & 0,04 & 0,22 \\
\hline Jacaranda jasminoides & 4,78 & 3,91 & 3,08 & 3,92 & 1,78 & 2,87 & 1,07 & 1,91 & 1,93 & 2,25 & 1,51 & 1,90 \\
\hline Jacaratia spinosa & & & & & & & & & 0,11 & 0,20 & 0,02 & 0,11 \\
\hline Kielmeyera lathrophyton & 5,17 & 1,50 & 5,59 & 4,09 & & & & & 0,90 & 1,02 & 0,93 & 0,95 \\
\hline Lafoensia pacari & & & & & & & & & 0,11 & 0,20 & 0,48 & 0,26 \\
\hline $\begin{array}{l}\text { Lamanonia } \\
\text { grandistipularis }\end{array}$ & & & & & & & & 0,11 & 0,20 & 0,06 & 0,12 & \\
\hline Lamanonia ternata & & & & & & & & & 0,11 & 0,20 & 0,02 & 0,11 \\
\hline Leandra sp. & 0,19 & 0,30 & 0,07 & 0,19 & & & & & & & & \\
\hline Licania hoehnei & & & & & & & & & 0,11 & 0,20 & 0,03 & 0,11 \\
\hline Licania kunthiana & & & & & & & & & 0,45 & 0,20 & 0,16 & 0,27 \\
\hline Licania octandra & & & & & & & & & 0,11 & 0,20 & 0,02 & 0,11 \\
\hline Licara armeniaca & 0,19 & 0,30 & 0,49 & 0,33 & & & & & & & & \\
\hline Luehea divaricata & 0,10 & 0,30 & 0,12 & 0,17 & 0,10 & 0,24 & 0,05 & 0,13 & 0,11 & 0,20 & 0,18 & 0,16 \\
\hline Luehea grandiflora & & & & & 0,41 & 0,48 & 0,37 & 0,42 & 0,90 & 0,61 & 1,13 & 0,88 \\
\hline Mabea fistulifera & 1,19 & 0,90 & 0,83 & 0,97 & 23,10 & 3,11 & 14,10 & 13,40 & 0,11 & 0,20 & 0,03 & 0,11 \\
\hline Machaerium acutifolium & & & & & & & & 0,45 & 0,82 & 1,08 & 0,78 & \\
\hline Machaerium amplum & 0,89 & 1,80 & 0,33 & 1,01 & 0,41 & 0,95 & 0,23 & 0,53 & & & & \\
\hline Machaerium brasiliense & 8,66 & 3,31 & 9,21 & 7,06 & 2,61 & 2,63 & 4,41 & 3,22 & 0,34 & 0,61 & 0,12 & 0,35 \\
\hline Machaerium nyctitans & & & & & 1,15 & 2,15 & 0,89 & 1,40 & 3,85 & 2,05 & 4,76 & 3,55 \\
\hline Machaerium opacum & & & & & & & & & 0,11 & 0,20 & 0,06 & 0,12 \\
\hline Machaerium sp1 & & & & & 0,10 & 0,24 & 0,02 & 0,12 & & & & \\
\hline Maprounea guianensis & & & & & 0,20 & 0,48 & 0,26 & 0,31 & 0,22 & 0,20 & 0,31 & 0,25 \\
\hline Margaritaria nobilis & & & & & & & & & 1,93 & 1,23 & 1,54 & 1,56 \\
\hline Marlierea racemosa & 0,19 & 0,60 & 0,56 & 0,45 & & & & & & & & \\
\hline Matayba mollis & & & & & & & & & 0,11 & 0,20 & 0,02 & 0,11 \\
\hline Maytenus gonoclada & 0,19 & 0,30 & 0,14 & 0,21 & 0,20 & 0,48 & 0,09 & 0,26 & & & & \\
\hline Maytenus ilicifolia & 0,19 & 0,60 & 0,08 & 0,29 & 0,10 & 0,24 & 0,04 & 0,12 & 0,34 & 0,41 & 0,06 & 0,27 \\
\hline Maytenus robusta & 0,19 & 0,60 & 0,12 & 0,31 & & & & & 0,11 & 0,20 & 0,01 & 0,11 \\
\hline Melanoxylon brauna & & & & & 0,73 & 1,19 & 1,54 & 1,15 & 1,58 & 0,61 & 1,76 & 1,32 \\
\hline Meliosma sellowii & & & & & & & & & 0,11 & 0,20 & 0,03 & 0,11 \\
\hline MF 01 & 0,89 & 1,20 & 0,28 & 0,79 & & & & & & & & \\
\hline MF 02 & 1,59 & 2,10 & 0,87 & 1,52 & 0,94 & 1,91 & 0,37 & 1,07 & & & & \\
\hline MF 03 & 0,10 & 0,30 & 0,02 & 0,14 & & & & & & & & \\
\hline MF 04 & & & & & 0,10 & 0,24 & 0,06 & 0,13 & & & & \\
\hline
\end{tabular}

Paschoal., E., M.., A., D., Otoni., T., J., O., Gripp., A., M., Freire., J., P., Alves., P., L., Gonzaga., A., P., D., Machado., E., L., $M$. 
MF 05

\section{Continuação}

MF 06

MF 07

MF 08

MF 09

MF 10

MF 11

MF 12

MF 13

MF 15

MF 16

MF 17

MF 18

MF 19

MF 20

MF 21

MF 22

MF 23

MF 24

MF 25

Miconia cuspidata

Miconia minutiflora

Micropholis gardneriana

Micropholis venulosa

Mouriri glazioviana

Myracrodruon urundeuva

Myrcia amazonica

Myrcia eriocalyx

Myrcia guianensis

Myrcia mischophylla

Myrcia sp.

Myrcia splendens

Myrcia tenuifolia

Myrsine coriacea

Myrsine guianensis

Myrsine umbellata

Myrsine venulosa

Nectandra lanceolata

Nectandra nitidula

Nectandra oppositifolia

Ocotea corymbosa

Ocotea diospyrifolia
$0,10 \quad 0,24 \quad 0,06 \quad 0,13$

$0,10 \quad 0,24 \quad 0,05 \quad 0,13$

$\begin{array}{llll}0,10 & 0,24 & 0,02 & 0,12\end{array}$

$0,10 \quad 0,24 \quad 0,02 \quad 0,12$

$0,10 \quad 0,24 \quad 0,12 \quad 0,15$

$\begin{array}{llll}0,20 & 0,48 & 0,13 & 0,27\end{array}$

$0,10 \quad 0,24 \quad 0,02 \quad 0,12$

$0,10 \quad 0,30 \quad 0,02 \quad 0,14$

$0,10 \quad 0,24 \quad 0,01 \quad 0,12$

$\begin{array}{llll}0,10 & 0,21 & 0,07 & 0,13\end{array}$

$\begin{array}{llll}0,10 & 0,24 & 0,09 & 0,14\end{array}$

$0,10 \quad 0,30 \quad 0,08 \quad 0,16$

$0,10 \quad 0,30 \quad 0,15 \quad 0,18$

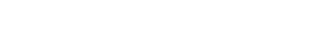$$
\begin{array}{llll}
0,11 & 0,20 & 0,25 & 0,19
\end{array}
$$$$
0,11 \quad 0,20 \quad 1,01 \quad 0,44
$$$$
\begin{array}{llll}
0,11 & 0,20 & 0,03 & 0,11
\end{array}
$$$$
0,11 \quad 0,20 \quad 1,80 \quad 0,70
$$$$
0,22 \quad 0,41 \quad 0,01 \quad 0,21
$$$$
\begin{array}{llll}
0,34 & 0,20 & 0,54 & 0,36
\end{array}
$$$$
0,11 \quad 0,20 \quad 0,02 \quad 0,11
$$$$
\begin{array}{llll}
0,11 & 0,20 & 0,23 & 0,18
\end{array}
$$$$
\begin{array}{llll}
0,22 & 0,20 & 0,52 & 0,32
\end{array}
$$$$
1,58 \quad 1,43 \quad 0,34 \quad 1,12
$$

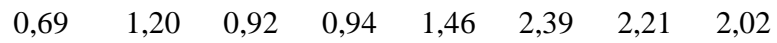$$
\begin{array}{llll}
0,11 & 0,20 & 0,50 & 0,27
\end{array}
$$$$
\begin{array}{llllllll}
0,41 & 0,95 & 0,69 & 0,69 & 2,04 & 1,43 & 1,41 & 1,63
\end{array}
$$$$
\begin{array}{llllllllllll}
10,70 & 4,21 & 9,19 & 8,02 & 0,83 & 1,19 & 0,59 & 0,87 & 0,11 & 0,20 & 2,08 & 0,80
\end{array}
$$$$
\begin{array}{llll}
0,29 & 0,90 & 0,07 & 0,42
\end{array}
$$$$
\begin{array}{llllllll}
2,78 & 3,91 & 2,13 & 2,94 & 1,46 & 1,67 & 0,86 & 1,33
\end{array}
$$$$
\begin{array}{llll}
0,39 & 0,90 & 0,16 & 0,48
\end{array}
$$$$
\begin{array}{lllll}
0,31 & 0,48 & 0,43 & 0,40
\end{array}
$$$$
\begin{array}{llllllllllll}
2,78 & 2,41 & 2,13 & 2,44 & 1,36 & 0,95 & 0,56 & 0,96 & 1,02 & 1,43 & 0,04 & 0,83
\end{array}
$$$$
1,15 \quad 1,91 \quad 1,56 \quad 1,54
$$$$
0,59 \quad 0,60 \quad 0,19 \quad 0,46
$$$$
0,10 \quad 0,30 \quad 0,02 \quad 0,14
$$$$
0,22 \quad 0,20 \quad 0,16 \quad 0,19
$$$$
\begin{array}{llll}
0,56 & 0,82 & 0,17 & 0,52
\end{array}
$$$$
0,11 \quad 0,20 \quad 0,15 \quad 0,15
$$$$
\begin{array}{llllllll}
0,20 & 0,48 & 0,27 & 0,32 & 0,56 & 0,61 & 0,08 & 0,42
\end{array}
$$$$
0,10 \quad 0,24 \quad 0,02 \quad 0,12
$$$$
1,13 \quad 1,43 \quad 0,01 \quad 0,86
$$

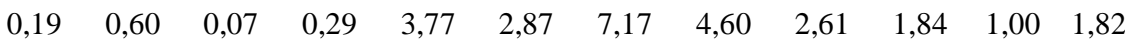$$
1,58 \quad 1,43 \quad 0,53 \quad 1,18
$$

Paschoal., E., M.., A., D., Otoni., T., J., O., Gripp., A., M., Freire., J., P., Alves., P., L., Gonzaga., A., P., D., Machado., E., L., M. 
Revista Brasileira de Geografia Física v.014, n.04 (2021) 2265-2284

\begin{tabular}{|c|c|c|c|c|c|c|c|c|c|c|c|c|}
\hline \multirow{2}{*}{\multicolumn{13}{|c|}{$\begin{array}{l}\text { Ocotea odorifer } \\
\text { Continuação }\end{array}$}} \\
\hline & & & & & & & & & & & & \\
\hline Ocotea spixiana & 0,10 & 0,30 & 0,03 & 0,14 & & & & & 0,34 & 0,20 & 0,95 & 0,49 \\
\hline Ocotea velloziana & & & & & & & & & 0,11 & 0,20 & 0,08 & 0,13 \\
\hline Ormosia arborea & 0,10 & 0,30 & 0,11 & 0,17 & & & & & 0,45 & 0,61 & 1,94 & 1,00 \\
\hline Ormosiavicosana & & & & & & & & & 0,45 & 0,61 & 0,39 & 0,48 \\
\hline Ouratea salicifolia & & & & & 0,52 & 0,95 & 0,32 & 0,60 & & & & \\
\hline Panopsis rubescens & 1,79 & 2,41 & 2,49 & 2,23 & 0,10 & 0,24 & 0,05 & 0,13 & & & & \\
\hline Pera glabrata & 10,4 & 3,01 & 8,85 & 7,44 & & & & & & & & \\
\hline Persea rufotomentosa & & & & & & & & & 0,11 & 0,20 & 1,23 & 0,51 \\
\hline Phyllanthus acuminatus & & & & & & & & 0,11 & 0,20 & 0,11 & 0,14 & \\
\hline $\begin{array}{l}\text { Pimenta } \\
\text { pseudocaryophyllus }\end{array}$ & & & & 0,31 & 0,48 & 0,31 & 0,37 & 0,68 & 1,02 & 0,02 & 0,57 & \\
\hline Platycyamus regnellii & & & & & 0,10 & 0,24 & 0,05 & 0,13 & 0,34 & 0,41 & 1,57 & 0,77 \\
\hline Platypodium elegans & 0,10 & 0,30 & 0,07 & 0,15 & 2,82 & 1,19 & 3,28 & 2,43 & 1,02 & 0,82 & 0,01 & 0,62 \\
\hline Pouteria gardneri & & & & & & & & & 0,22 & 0,20 & 0,09 & 0,17 \\
\hline Pouteria microstrigosa & & & & & 0,10 & 0,24 & 0,18 & 0,17 & & & & \\
\hline Protium spruceanum & & & & & 0,10 & 0,24 & 1,05 & 0,46 & & & & \\
\hline Prunus myrtifolia & & & & & 0,31 & 0,71 & 0,51 & 0,51 & 1,58 & 1,43 & 0,52 & 1,18 \\
\hline $\begin{array}{l}\text { Pseudobombax } \\
\text { longiflorum }\end{array}$ & & & & & & & & 0,45 & 0,41 & 2,29 & 1,05 & \\
\hline Psidium sp. & 0,10 & 0,30 & 0,17 & 0,19 & & & & & & & & \\
\hline Psychotria deflexa & & & & & & & & & 0,22 & 0,41 & 0,37 & 0,33 \\
\hline Psychotria sp. & 0,10 & 0,30 & 0,22 & 0,20 & & & & & & & & \\
\hline Psychotria vellosiana & & & & & 0,20 & 0,48 & 0,09 & 0,26 & 0,22 & 0,41 & 0,09 & 0,24 \\
\hline Qualea selloi & & & & & & & & & 0,11 & 0,200 & 0,02 & 0,11 \\
\hline Qualea sp. & 10,00 & 0,30 & 0,17 & 0,19 & 0,52 & 0,72 & 0,31 & 0,52 & & & & \\
\hline Richeria grandis & & & & & & & & & 1,02 & 0,82 & 0,03 & 0,62 \\
\hline Roupala montana & 0,19 & 0,30 & 0,12 & 0,20 & 0,20 & 0,24 & 0,23 & 0,22 & 0,11 & 0,20 & 0,03 & 0,11 \\
\hline Schefflera angustissima & 0,59 & 1,20 & 0,15 & 0,65 & 0,20 & 0,48 & 0,05 & 0,24 & & & & \\
\hline Schefflera macrocarpa & & & & & & & & & 0,22 & 0,41 & 0,06 & 0,23 \\
\hline Schefflera vinosa & & & & & & & & & 0,34 & 0,61 & 0,09 & 0,35 \\
\hline Senna macranthera & 0,10 & 0,30 & 0,05 & 0,15 & & & & & & & & \\
\hline Siparuna guianensis & 0,10 & 0,30 & 0,03 & 0,14 & 0,94 & 1,43 & 0,34 & 0,91 & 3,97 & 2,25 & 0,21 & 2,14 \\
\hline Siphoneugena densiflora & 0,10 & 0,30 & 0,03 & 0,14 & & & & & & & & \\
\hline $\begin{array}{l}\text { Siphoneugena } \\
\text { kiaerskoviana }\end{array}$ & 0,69 & 1,50 & 1,12 & 1,10 & & & & & & & & \\
\hline Sloanea guianensis & 0,79 & 0,90 & 0,91 & 0,87 & 0,62 & 0,71 & 1,45 & 0,93 & & & & \\
\hline Sloanea monosperma & 0,19 & 0,60 & 0,03 & 0,27 & 1,46 & 2,15 & 1,41 & 1,67 & 0,45 & 0,82 & 0,17 & 0,48 \\
\hline Sloanea pubescens & & & & & & & & & 0,11 & 0,20 & 1,97 & 0,76 \\
\hline Sloanea retusa & & & & & 0,20 & 0,24 & 0,11 & 0,18 & 0,11 & 0,20 & 2,88 & 1,06 \\
\hline Sloanea stipitata & & & & & & & & & 0,22 & 0,20 & 0,03 & 0,15 \\
\hline Solanum swartzianum & 0,29 & 0,60 & 0,16 & 0,35 & 0,31 & 0,48 & 0,09 & 0,29 & & & & \\
\hline Sorocea guilleminiana & & & & & & & & & 0,11 & 0,20 & 0,14 & 0,15 \\
\hline $\begin{array}{l}\text { Sparattosperma } \\
\text { leucanthum }\end{array}$ & & & & & & & & 0,22 & 0,41 & 0,02 & 0,22 & \\
\hline
\end{tabular}

Paschoal., E., M.., A., D., Otoni., T., J., O., Gripp., A., M., Freire., J., P., Alves., P., L., Gonzaga., A., P., D., Machado., E., L., $M$. 


\section{Continuação}

Stryphnodendron polyphyllum

Styrax latifolius

Swartzia acutifolia

Swartzia apetala

Tabernaemontana hystrix

Tachigali paratyensis

Tachigali rugosa

Talisia esculenta

Tapirira guianensis

Tapirira obtusa

Terminalia glabrescens

Thyrsodium spruceanum

Tibouchina arborea

Tibouchina estrellensis

Tibouchina sp.

Trichilia catigua

Trichilia hirta

Trichilia pallens

Trichilia pallida

Triplaris gardneriana

Virola bicuhyba

Vismia guianensis

Vismia martiana

Vismia micrantha

Vitex megapotamica

Vitex polygama

Vitex sellowiana

Vochysia oppugnata

Xylopia brasiliensis

Xylopia sericea

Xylosma ciliatifolia

Xylosma prockia

Zanthoxylum caribaeum
$0,10 \quad 0,24$

0,18

0,17

0,34

0,61

$0,10 \quad 0,35$

$0,22 \quad 0,41 \quad 0,21 \quad 0,28$

$0,34 \quad 0,61 \quad 0,18 \quad 0,37$

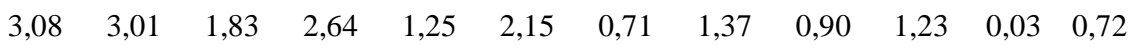

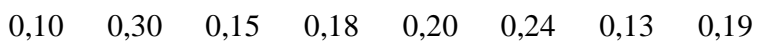

$0,10 \quad 0,30 \quad 0,02 \quad 0,14$

0,6

$$
1,20 \quad 2,12
$$

$$
1,34
$$

0,6

$$
0,62 \quad 0,95 \quad 3,78 \quad 1,79
$$

$2,95 \quad 2,25 \quad 1,92 \quad 2,37$

$0,11 \quad 0,20 \quad 0,47 \quad 0,26$

$0,10 \quad 0,24 \quad 0,73 \quad 0,36$

$\begin{array}{llll}0,11 & 0,20 & 0,80 & 0,37\end{array}$

$0,20 \quad 0,48 \quad 0,45 \quad 0,38$

$0,31 \quad 0,71 \quad 0,96 \quad 0,66$

\begin{tabular}{|c|c|c|c|c|c|c|c|c|c|c|c|}
\hline & & & & & & & & 0,11 & 0,20 & 0,35 & 0,22 \\
\hline & & & & 2,82 & 2,15 & 6,37 & 3,78 & & & & \\
\hline & & & & & & & & 0,22 & 0,41 & 0,21 & 0,28 \\
\hline & & & & & & & & 0,11 & 0,20 & 0,12 & 0,14 \\
\hline 0,10 & 0,30 & 2,08 & 0,82 & 0,10 & 0,24 & 0,38 & 0,24 & 0,68 & 0,82 & 0,66 & 0,72 \\
\hline & & & & & & & & 0,68 & 0,61 & 0,76 & 0,68 \\
\hline & & & & & & & & 1,58 & 1,02 & 0,01 & 0,87 \\
\hline & & & & & & & & 0,22 & 0,41 & 0,01 & 0,21 \\
\hline 0,29 & 0,60 & 0,15 & 0,35 & 0,10 & 0,24 & 0,06 & 0,13 & & & & \\
\hline 0,39 & 1,20 & 0,11 & 0,57 & 0,20 & 0,24 & 0,11 & 0,18 & 0,45 & 0,61 & 0,02 & 0,36 \\
\hline & & & & 0,20 & 0,24 & 0,06 & 0,17 & 0,45 & 0,61 & 0,06 & 0,37 \\
\hline & & & & 0,94 & 1,43 & 0,31 & 0,89 & & & & \\
\hline 2,19 & 3,31 & 1,17 & 2,22 & & & & & & & & \\
\hline & & & & & & & & 0,22 & 0,41 & 0,01 & 0,21 \\
\hline & & & & 0,10 & 0,24 & 0,02 & 0,12 & 0,22 & 0,41 & 0,06 & 0,23 \\
\hline 0,29 & 0,60 & 0,10 & 0,33 & & & & & 0,90 & 1,23 & 0,03 & 0,72 \\
\hline & & & & & & & & 0,68 & 0,61 & 0,11 & 0,47 \\
\hline & & & & 0,10 & 0,24 & 0,04 & 0,13 & & & & \\
\hline & & & & & & & & 0,11 & 0,20 & 0,01 & 0,11 \\
\hline
\end{tabular}

$$
\begin{array}{llllllll}
0,10 & 0,24 & 0,02 & 0,12 & 0,34 & 0,20 & 0,11 & 0,22
\end{array}
$$

$0,19 \quad 0,60 \quad 0,05 \quad 0,28$

Zanthoxylum rhoifolium

$\mathrm{DR}=$ Densidade relativa; $\mathrm{FR}=$ Frequência relativa; $\mathrm{DoR}=$ Dominância Relativa; $\mathrm{VI}=$ Valor de importância.

A espécie Amaioua guianensis apresentou, no trecho do interior, baixa densidade, mas a terceira maior dominância relativa, o que aponta para presença de indivíduos de grande porte. No trecho de borda em contato com o café esta espécie também está entre as mais importantes na estrutura da comunidade. Entretanto, neste trecho, A. guianensis apresentou maiores densidade e frequência relativas e menor área basal, o que indica que os indivíduos

Paschoal., E., M.., A., D., Otoni., T., J., O., Gripp., A., M., Freire., J., P., Alves., P., L., Gonzaga., A., P., D., Machado., E., L., M. 
estabelecidos nesse trecho são mais finos do que os presentes no interior.

Assim ficou claro por meio da análise do VI que o compartilhamento de espécies importantes entre os trechos foi baixo, contemplando apenas duas espécies. Casearia arbórea e Ocotea corymbosa foram comuns aos trechos interior e borda da pastagem, Amaioua guianensis e Jacaranda jasminoides tiveram relevância nos trechos do interior e do café e, entre as duas bordas, apenas uma espécie importante foi comum, Machaerium brasiliense. Nenhuma das 10 espécies classificadas pelo VI foi importante em todos os três trechos, o que reforça a dissimilaridade entre eles.

A distribuição diamétrica do tipo $J$ invertido sugere a possibilidade de reposição da comunidade arbórea por indivíduos mais jovens, o que pode ser verificado em todos os trechos. Assim sendo, verificou-se gradiente diamétrico entre os três trechos, sendo a BC caracterizada pela elevada presença de indivíduos finos, situados em sua maioria nas primeiras classes, seguido pela BP que apresentou maior frequência de indivíduos na segunda classe. Por fim, o interior foi caracterizado pela maior presença de indivíduos com diâmetros maiores (DAP $\geq 40 \mathrm{~cm}$ ).

O predomínio do número de indivíduos na primeira classe de diâmetro e poucos indivíduos grandes na BC estão, provavelmente, associados aos distúrbios ocorridos no passado, como o corte seletivo e ocorrência de fogo, embora a influência do fator borda não possa ser descartada (Trindade et al, 2019).

Quando comparada à $\mathrm{BC}$, estrutura da $\mathrm{BP}$ apresentou maior área basal, presença de indivíduos maiores e menor densidade de indivíduos, o que pode estar relacionado ao fato deste trecho ter sofrido, em menor intensidade, distúrbios antrópicos como corte seletivo e fogo. Já o trecho do interior se distinguiu dos demais por possuir maior área basal $\left(13,82 \mathrm{~m}^{2}\right.$.ha- $\left.\mathrm{a}^{-1}\right)$, o que reforça o padrão apresentado pela distribuição diamétrica com a presença de indivíduos de diâmetros maiores.

A teoria do efeito de borda compreende que os limites florestais em contato com paisagens abertas, como a pastagem, tendem a sofrer de maneira mais acentuada os efeitos do vento, provocando queda de árvores e abertura de clareiras, além da maior exposição luminosa e a diminuição da umidade, e, assim, consequentemente, sua estrutura é caracterizada por elevada densidade de indivíduos finos (Metzger, 1998; Roquette, 2018). Entretanto, os resultados deste estudo não corroboram a teoria do efeito de borda no que diz respeito à influência dos tipos de contato, e pode indicar que a presença de distúrbios antrópicos neutraliza a influência do contato com bordas florestais.

Em contrapartida, BC obteve a maior densidade e a menor área basal $\left(8,83 \mathrm{~m}^{2} \cdot \mathrm{ha}^{-1}\right)$, corroborando novamente a interpretação de que a estrutura diamétrica desse trecho é composta, em sua maioria, por indivíduos mais finos. BP apresentou situação intermediária às observadas em BC e interior, com área basal igual 10,46 $\mathrm{m}^{2}$.ha ${ }^{-1}$. Embora esses dados revelem a característica de cada um dos trechos, os valores de área basal não foram significativamente diferentes $(\mathrm{p}>0,05)$.

Em relação a estrutura encontrada nas bordas, o trecho do interior abriga indivíduos de maiores dimensões, maior área basal e menor densidade e, ao mesmo tempo, mantém uma reserva de indivíduos nas menores classes. Tais características estruturais são consideradas típicas de florestas em estágio avançado de sucessão e indicam que o interior do fragmento ainda apresenta trechos de floresta bem conservados (Zanii et al, 2014).

\section{Conclusão}

A área de estudo possui alta riqueza e diversidade de espécies com composição florística entre os trechos bastante dissimilares. A borda do café mostrou-se menos conservada por apresentar características estruturais semelhantes àquelas de florestas em desenvolvimento inicial. Já a borda da pastagem possui maior diversidade e riqueza de espécies e sua estrutura se caracteriza pela presença indivíduos maiores e maior área basal.

As espécies ameaçadas de extinção indicam a importância e necessidade de conservação dos remanescentes de Floresta Estacional Semidecidual na região e do manejo adequado da vegetação da RPPN Fartura, para a preservação de parte da biodiversidade regional. Especialmente se considerado que pouco se conhece acerca das porções florestais (remanescentes de Mata Atlântica) existentes ao longo da Reserva da Biosfera Serra do Espinhaço, que é um território que engloba características

2281

Paschoal., E., M.., A., D., Otoni., T., J., O., Gripp., A., M., Freire., J., P., Alves., P., L., Gonzaga., A., P., D., Machado., E., L., $M$. 
variadas e singulares, com alto grau de endemismo, conforme foi observado no presente trabalho.

Logo, é de tamanha importância se conhecer os aspectos florísticos e estruturais dos remanescentes de Mata Atlântica da Reserva da Biosfera da Serra do Espinhaço, assim como o de promover o conhecimento e a implementação de políticas públicas baseadas em estudos científicos para a sua conservação e manejo, assim como estimular as relações entre o meio ambiente e as comunidades próximas, evitando demandas antrópicas acima da capacidade de suporte destes ambientes.

\section{Agradecimentos}

Este trabalho com apoio da Coordenação de Aperfeiçoamento Pessoal de Nível Superior (CAPES) -Código de Financiamento 001. E apoio financeiro da Fundação de Amparo à Pesquisa do Estado de Minas Gerais (FAPEMIG) e da Companhia Energética de Minas (CEMIG).

\section{Referências}

Andrade, M.A., Martins, C.S., Domingues, A.S., 2015. Primeira Revisão Periódica da Reserva da Biosfera da Serra do Espinhaço. Reserva da Biosfera da Serra do Espinhaço, MaB-UNESCO. Belo Horizonte, Minas Gerais, Brasil. fevereiro.

APG IV., 2016. An update of the Angiosperm Phylogeny Group classification for the orders and families of flowering plants: APG IV. Botanical Journal of the Linnean Society. 181, 1-20.

Baars, F.J., Grossi-Sad, J.H., Fonseca, E., 1997. Geologia da Folha Capelinha. Projeto Espinhaço Belo Horizonte, COMIG - Companhia Mineradora de Minas Gerais, 1373-1503.

Barbalho, M.G.S., Silva, S.D., Giustina, C.D., 2015. Avaliação Temporal do Perfil da Vegetação da Microrregião de Ceres Através do uso de Métricas de Paisagem. Boletim Goiano de Geografia, vol. 35, núm. 3, set-dez, 472- 487.

Botrel, R.T., Oliveira-Filho, A.T., Rodrigues, L.A., Curi, N., 2002. Influência do solo e topografia sobre as variações da composição florística e estrutura da comunidade arbóreo-arbustiva de uma floresta estacional semidecidual em Ingaí, MG. Revista Brasileira de Botânica, 25, 2, jun, p.195213, doi: 10.1590/S0100-84042002000200008.

Braga, A.J.T., Borges, E.E.D.L., Martins, S.V., 2015. Influência dos fatores edáficos na variação florística de Floresta Estacional Semidecidual, em Viçosa,
MG. Revista Árvore, vol. 39, aug, p. 623-633, doi: 10.1590/0100-67622015000400004.

Brasil. Ministério do Meio Ambiente, 2010. Portaria ${ }^{\circ}$ 444 , de 26 de novembro de 2010. Reconhece como mosaico de unidades de conservação no Estado de Minas Gerais, o Mosaico do Espinhaço: Alto Jequitinhonha - Serra do Cabral. Brasília.

Brasil. Ministério do Meio Ambiente, 2014. Portaria ${ }^{\circ}$ 443, de 17 de dezembro de 2014. Reconhece como espécies da flora brasileira ameaçadas de extinção aquelas constantes da "Lista Nacional Oficial de Espécies da Flora Ameaçadas de Extinção". Brasília.

Brower, J.E., Zar, J.H., 1984. Field \& laboratory methods for general ecology.Boston: W.C. Brown Publishers.

Cardoso, J. T., 2016. A Mata Atlântica e sua conservação. Revista Encontros Teológicos, v. 31, n. 3, set-dez., p. 441-458.

Chazdon, R.L., 2016. Renascimento de florestas: regeneração na era do desmatamento. Oficina de Textos, $432 \mathrm{p}$.

Connel, J.H., 1978. Diversity in tropical rain forest and coral reefs. Science, vol. 199.

Costa, G.C., Hampe, A., Ledru, M.P., Martinez, P.A., Mazzochini, G.G., Shepard, D.B., Werneck, F.P., Moritz, C., Carnaval, A.C., 2018. Biome stability in South America over the last $30 \mathrm{kyr}$ : Inferences from long-term vegetation dynamics and habitat modelling. Global Ecology and Biogeography, 27, mar. 285-297, doi: 10.1111/geb.12694.

Cruz, A.P., Higuchi, P., Silva, A.C., Kilca, R.V., Dallabrida, J.P., Souza, K., Lima, C.L., Soboleski, V.F., Nunes, A.S., Loebens, R., 2018. Inter-relação entre paisagem, organização florístico-estrutural e demografia do componente arbóreo em floresta com araucárias. Ciência Florestal, 28, jan-mar, 6779, doi: 10.5902/1980509831579.

Esser, L.F., Neves, D.M., Jarenkow, J.A., 2019. Habitat-specific impacts of climate change in the Mata Atlântica biodiversity hotspot. Diversity and Distributions, 25, 12, dez,. 1846-1856, doi: 10.1111/ddi.12984.

Estevan, D.A., Vieira, A.O.S., Gorenstein, M.R., 2016. Estrutura e relações florísticas de um fragmento de Floresta Estacional Semidecidual, Londrina, Paraná, Brasil. Ciência Florestal. jul-set. 713-725, doi: 10.5902/1980509824195.

Ferreira, O.V., Silva, M.M., 2012. O clima da bacia do rio Jequitinhonha, em Minas Gerais: subsídios para a gestão de recursos hídricos. Revista Brasileira de Geografia Física, 2, 302-319.

Flora do Brasil 2020 em construção. Jardim Botânico do Rio de Janeiro. Disponível em: < http://floradobrasil.jbrj.gov.br/ >. Acesso em: 05 março de 2020.

Fontana, C., Sevegnani, L., 2012. Quais são as espécies arbóreas comuns da Floresta Estacional Decidual?

Paschoal., E., M.., A., D., Otoni., T., J., O., Gripp., A., M., Freire., J., P., Alves., P., L., Gonzaga., A., P., D., Machado., E., $L ., M$. 
Revista de Estudos Ambientais. 14. 74-88, doi: 10.7867/1983-1501.2012. 1474-88.

Forzza, R.C., Pifano, D.S., Oliveira-Filho, A.T., Meireles, L.D., Faria, P.L., Salimena, F.R., Prado, J., 2014. Flora vascular da Reserva Biológica da Represa do Grama, Minas Gerais, e sua relação florística com outras florestas do sudeste brasileiro. Rodriguésia, 65, abr-jun, 275-292, doi: $10.1590 / \mathrm{S} 2175-78602014000200001$.

Freitas, S.R., Hawbaker, T.J., Metzger, J.P., 2010. Effects of roads, topography, and land use on forest cover dynamics in the Brazilian Atlantic Forest. Forest ecology and management 259, jan, p. 410417, doi: 10.1016/j.foreco.2009.10.036.

Gauch, H. G., 1982. Multivariate analysis in community ecology. Cambridge: Cambridge University Press.

Giulietti, A.M., Menezes, N., Mendonça, M., Lins, L., 2000. Campos rupestres. Lista Vermelha das espécies ameaçadas de extinção da flora de Minas Gerais. Belo Horizonte: Fundação Biodiversitas/Fundação Zoobotânica.

Gonzaga, A.P.D., Machado, E.L.M., Almeida, H.S., Nunes, Y.R.F., 2017a. Interação espécie-ambiente no componente regenerante de Floresta Estacional Decidual no sudeste do Brasil. Heringeriana, 11, . 39-57.

Gonzaga, A.P.D., Machado, E.L.M., Felfili, J.M., Pinto, J.R.R., 2017b. Brazilian Decidual Tropical Forest enclaves: floristic, structural and environmental variations. Brazilian Journal of Botany, 26, .1-10, doi: 10.1007/s40415-016-0346-z.

Gonzaga, A.P.D., Pinto, J.R.R., Machado, E.L.M., Felfili, J.M., 2013. Similaridade florística entre estratos da vegetação em quatro Florestas Estacionais Deciduais na bacia do Rio São Francisco. Rodriguésia, vol. 64, n. 1, jan-mar, p. 11-19, doi: 10.1590/S2175-78602013000100002.

Hobbs, R.J., 2002. The ecological context: a landscape perspective. Nova Iorque: CambrigdeUniversity Press, vol. 1. Perrow, M.R., Davy, A.J. Handbook of Ecological Restoration: principles of restoration. p. 279-299.

Instituto Brasileiro de Geografia e Estatística - IBGE. Manual Técnico de Geomorfologia, 2009. Manuais técnicos em geociências $2^{\mathrm{a}}$ ed. Rio de Janeiro: IBGE.

Jessie, P., Santos, T., Sobral-Souza, K.S., Brown Jr, M.H.V., Ribeiro, M.C., Freitas, A.V.L., 2020. Effects of landscape modification on species richness patterns of fruit-feeding butterflies. Brazilian Atlantic Forest Diversity and Distributions, 26, 196-208, doi: 10.1111/ddi.13007.

Joly, C.A., Metzger, J. P., Tabarelli, M., 2014. Experiences from the Brazilian Atlantic Forest: ecological findings and conservation initiatives. New Phytologist, nov, p. 459-473, doi: 10.1016/j.biocon.2009.02.021.
Kageyama, P.Y., Oliveira, R.E., Gandara, F.B., 2003. Biodiversidade e restauração da floresta tropical. 1a ed. Botucatu: Fundação de Estudos e Pesquisas Agrícolas Florestais. Kageyama, P.Y., Oliveira, R.E., Moraes, L.F.D., Engel, V.L.; Gandara, F.B. (Orgs.) Restauração ecológica de ecossistemas naturais.

Kent, M., Coker, P., 1992. Vegetation description analyses. London: Behaven Press.

Laurance, W.F., 2009. Conserving the hottest of the hotspots. Biological Conservation, jun, p. 1137, doi:10.1016/j.biocon.2008.10.011.

Leigh Jr, E.G., Davidar, P., Dick, C.W., Terborgh, J., Puyravaud, J.P., terSteege, H., Wright, S.J., 2004. Why do some tropical forests have so many species of trees?.Biotropica, 36, dez, 447-47, doi: 10.1111/j.1744-7429.2004.tb00342.

Lepš, J., Šmilauer, P., 1999. Multivariate analysis of ecological data. Faculty of Biological Sciences, University of South Bohemia, ČeskéBudějovice, 110.

Lôbo, D., Leão, T., Melo, F.P., Santos, A.M., Tabarelli, M., 2011. Forest fragmentation drives Atlantic forest of northeastern Brazil to biotic homogenization. Diversity and Distributions, 17, mar, p. 287-296, doi: 10.1111/j.14724642.2010.00739.

Lorenzoni-Paschoa, L.D.S., Abreu, K.M.P.D., Silva, G.F.D., Dias, H.M., Machado, L.A., Silva, R.D.D., 2019. Estágio sucessional de uma floresta estacional semidecidual secundária com distintos históricos de uso do solo no sul do Espírito Santo. Rodriguésia, 70, 1-18, doi: 10.1590/21757860201970028.

Magurran, A.E., 2013. Measuring biological diversity. John Wiley \& Sons.

Metzger, J.P., 1998. Changements de la structure du paysage et richessespécifique des fragments forestiersdans le Sud-Est du Brésil. Comptes Rendus de L'Académie des Sciences,Serie III Sciences de La Vie, 321, 319-333, doi: 10.1016/S0764-4469(98)80058-9.

Minas Gerais (Estado). Instituto Estadual de Florestas, 2009. Deliberação $n^{\circ} 1.434$, de $1^{\circ}$ de setembro de 2009. Institui como Reserva Particular do Patrimônio Natural - RPPN a área denominada "Fartura", no município de Capelinha/MG. Belo Horizonte.

Ministério do Meio Ambiente - MMA, 2014. Portaria n. 443 , de 17 de dezembro de 2014. Diário Oficial da União, 18/12/2014, Seção 1, p. 110-121

Morandi, D.T., 2018. Delimitação de corredor ecológico entre unidades de conservação no cerrado brasileiro. [Dissertação]. Programa de PósGraduação em Ciência Florestal, Universidade Federal dos Vales do Jequitinhonha e Mucuri.

Morel, J.D., Pereira, J.A.A., Santos, R.M., AguiarCampos, N., Machado, E.L.M., 2018. Functional

Paschoal., E., M.., A., D., Otoni., T., J., O., Gripp., A., M., Freire., J., P., Alves., P., L., Gonzaga., A., P., D., Machado., E., L., M. 
characterisation of an anthropised Atlantic Forest fragment. Journal of Tropical Forest Science. jul; 537-545, doi: $30 . \quad 537-545$. $10.26525 / \mathrm{jtfs} 2018.30 .4 .537545$.

Mueller-Dombois, D., Ellenberg, H., 2002. Aims and methods of vegetation ecology. Caldwell: The Blackburn Press.

Oliveros, J.C., 2020. Venny. An interactive tool for comparing lists with Venn's diagrams. 2007-2015.

Porto, T.J., Pinto-da-Rocha, R., Rocha, P.L.B., 2018. Regional distribution patterns can predict the local habitat specialization of arachnids in heterogeneous landscapes of the Atlantic Forest. Diversity and Distributions, vol. 24, n.3/4, mar, p. 379-390, doi: 10.1111/ddi. 12685.

Pougy, N., Verdi M., Martins, E., Loyola, E.R., Martinelli, G., 2019. Plano de Ação Nacional para a conservação da flora ameaçada de extinção da Serra do Espinhaço Meridional. CNCFlora: Jardim Botânico do Rio de Janeiro: Laboratório de Biogeografia da Conservação: Andrea Jakobsson Estúdio, Rio de Janeiro.

Raymundo, D., Prado-Junior, J., Carvalho, F.A., Vales, V.S., Oliveira, P.E., van der Sande, M.T., 2019. Shifting species and functional diversity due to abrupt changes in water availability in tropical dry forests. J Ecol. jan; 107: 253- 264. doi:10.1111/1365-2745.13031

Ribeiro, M.C., Metzger, J.P., Martensen, A.C., Ponzoni, F.J., Hirota, M.M., 2009. The Brazilian Atlantic Forest: How much is left, and how is the remaining forest distributed? Implications for conservation. Biological conservation, jun, p. 11411153, doi: 10.1016/j.biocon.2009.02.021.

Ricklefs, R.E., Fangliang, E., 2016. Os efeitos da região influenciam a diversidade de espécies arbóreas locais. Anais da Academia Nacional de Ciências, p. 674-679.

Roquette, J.G., 2018. Distribuição da biomassa no cerrado e a sua importância na armazenagem do carbono. CiênciaFlorestal, 28, 1350-1363, doi: 10.5902/1980509833354.

Rozendaal, D.M., Bongers, F., Aide, T.M., AlvarezDávila, E., Ascarrunz, N., Balvanera, P., CalvoRodriguez, S., Chave, J., César, R.G., Chazdon, R.L., Condit, R., Dallinga, J.S., Almeida-Cortez, J.S., Jong, B., Oliveira, A., Denslow, J.S., Dent, D.H., DeWalt, S.J., Dupuy, J.M., Durán, S.M., Dutrieux, L.P., Espírito-Santo, M.M., Fandino, M.C., Fernandes, G.W., Finegan, B., García, H., Gonzalez, N., Moser, V.G., Hall, J.S., HernándezStefanoni, J.L., Hubbell, S., Jakovac, C.C., Hernández, A.J., Junqueira, A.B., Kennard, D., Larpin, D., Letcher, S.G., Licona, J.C., LebrijaTrejos, E., Marín-Spiotta, E., Martínez-Ramos, M., Massoca, P.E.S., Meave, J.A., Mesquita, R.C.G., Mora, F., Müller, S.C., Muñoz, R., Oliveira Neto, S.N., Norden, N., Nunes, Y.R.F., Ochoa-Gaona, S.,
Ortiz-Malavassi, E., Ostertag, R., Peña-Claros, M. Pérez-García, E.A., Piotto, D., Powers, J.S., Aguilar-Cano, J., Rodriguez-Buritica, S., Rodríguez-Velázquez, J., Romero-Romero, M.A., Ruíz, J., Sanchez-Azofeifa, A., Almeida, A.S., Silver, W.L., Schwartz, N.B., Thomas, W.W., Toledo, M., Uriarte, M., Sampaio, E.V.S., van Breugel, M., van der Wal, H., Martins, S.V., Veloso, M.D.M., Vester, H.F.M., Vicentini, A., Vieira, I.C.G., Villa, P., Williamson, G.B., Zanini, K.J., Zimmerman, J., Poorter, L., 2019. Biodiversity recovery of Neotropical secondary forests. Science advances., 5, 2019 mar., p. 1-10, doi: $0.1126 /$ sciadv.aau3114.

Sá Júnior, A., 2009. Aplicação da classificação de Köppen para o zoneamento climático do Estado de Minas Gerais. [Dissertação]. Universidade Federal de Lavras, p. 101.

Silva, V.L.D., Schmitt, J.L., 2015. The effects of fragmentation on Araucaria forest: analysis of the fern and lycophyte communities at sites subject to different edge conditions. Acta BotanicaBrasilica, 29, abr-jun, p. 223-230, doi: 10.1590/0102$33062014 a b b 3760$.

The Plant List. Versão 1.1, 2019. Disponível em: <http://www.theplantlist.org > Acesso em dezembro de 2019.

Tivy, F., 1993. Ecossystemstabilityanddisturbance. Essex: Longman Scientific \& Technical, Biogeography: a study of plants in the ecosphere; $\mathrm{p}$. 293-310.

Trindade, A.A., Sousa, J.P., Lourenço, R.W., 2019. Indicador dos Estágios de Sucessão de Fragmentos Florestais do Bioma Mata Atlântica. Revista Brasileira de Cartografia, 71 756-780, doi: 10.14393/rbcv71n3-48546.

Turner, M., Gardner, R.H., O`Neil, R.V., 1995. Ecological dynamics at broad scales. Bioscience, 45, s29-s35; doi: 10.2307/1312440.

Universidade Federal de Viçosa - UFV; Fundação Centro Tecnológico de Minas Gerais - CETEC; Universidade Federal de Lavras - UFLA; Fundação Estadual do Meio Ambiente. Mapa de solos do Estado de Minas Gerais. Belo Horizonte: FEAM, 2010.

Velazco, S.J.E., Villa Lobos, F., Galvão, F., De Marco Júnior, P., 2019. A dark scenario for Cerrado plant species: Effects of future climate, land use and protected areas ineffectiveness. Diversity and Distributions, 25, 660-673. abr, doi: 10.1111/12886.

Vieira, A.D., 2015. Flora, estrutura e funcionamento de um remanescente de Floresta Estacional Semidecidual em Capelinha, MG. [Dissertação]. Departamento de Engenharia Florestal. Universidade Federal dos Vales do Jequitinhonha e Mucuri. Diamantina, Minas Gerais; p.55.

Paschoal., E., M.., A., D., Otoni., T., J., O., Gripp., A., M., Freire., J., P., Alves., P., L., Gonzaga., A., P., D., Machado., E., L., $M$. 
Violle, C., Thuiller, W., Mouquet, N., Munoz, F., Kraft, N.J.B., Cadotte, M.W., Livingstone, S.W., Mouillot, D., 2017. Functional rarity: the ecology of outliers. Trends in Ecology \& Evolution, 32, . 5, mai. p. 356-367, doi: 10.1016/j.tree.2017.02.002.

Xie, H., He, Y., Zhang, N., Lu, H., 2017. Spatio temporal changes and fragmentation of forestland in Jiangxi Province, China. Journal of Forest Economics, n.29, dez p.4-13, ,doi: 10.1016/2017.08.004.
Zanini, K.J., Bergamin, R.S., Machado, R.E., Pillar, V.D., Müller, S.C., 2014. Atlantic rain forest recovery: successional drivers of floristic and structural patterns of secondary forest in Southern Brazil. Journal of vegetation science, 25, 4, jul, p. 1056-1068, doi: 10.1111/jvs.12162.

Zar, J.H., 1996. Biostatistical analysis. $3^{\text {a }}$ ed. New Jersey: Prentice-Hall. 